\title{
A utopia planetária de Pierre Lévy
}

\author{
The planetarian utopia of Pierre Lévy
}

Isa Maria Freire

Doutora em Ciência da Informação pela Universidade Federal do Rio de Janeiro - UFRJ Profa. adjunta do Departamento de Ciência da Informação da Universidade Federal da Paraíba - UFPB Presidente da Associação Nacional de Pesquisa em Ciência da Informação E-mail: isafreire@globo.com

\section{Resumo}

Relaciona as utopias visionárias de Pierre Levy e Mattelart às utopias documentalistas européias do século XIX, como as de Paul Otlet e La Fontaine, para afirmar a universalidade do conhecimento como uma questão ética. Nesta amarração teórica apresenta um gráfico sobre os constructos teóricos e metodológicos do campo científico da Ciência da Informação, em que autores e conceitos desenham um mapa tendo como atrator conceitual o constructo Inteligencia coletiva.

Palavras-chave: Ética da informação. Utopias planetárias. Inclusão digital

\begin{abstract}
It relates Lévy's and Mattelart's visionary utopias to the Europeans of ninethenth century, as they appear in documentalists Paul Otlet and La Fontaine to assure knowledge universality as an ethical issue. Around this theoretical construction, a graphic emerges to show theoretical and methodological constructions of Information Science as a field, where authors and concepts draw a map having as conceptual atractor, collective intelligence.
\end{abstract}

Keywords: Information Ethics. Planetary utopianisms. Digital inclusion

Apresentamos neste artigo, uma rede conceitual sobre ética da informação para a sociedade presente e futura, cujos indícios logramos encontrar na Inteligencia Coletiva de Pierre Levy (2000) e na História da utopia planetária de Armand Mattelart (2002). A proposta de Inteligencia Coletiva de Pierre Levy apresenta muitas das características de utopias citadas por Matellart (idem) e registradas ao longo da historia humana registrada.

Para Lévy (2000, p.60) podemos estar vivendo "um desses momentos extremamente raros em que uma civilização inventa a si própria, deliberadamente [de modo que] em pouco tempo, teremos passado [...] de uma humanidade a outra". Nesse processo, "escolhas políticas e culturais fundamentais abrem-se diante dos governos, dos grandes atores econômicos, dos cidadãos. Não se trata apenas de raciocinar em termos de impacto [...] mas também em termos de projeto" (LÉVY, 2000, p.13. Em itálico, no original). Esse projeto seria coletivo, representando a oportunidade para o exercício de um novo humanismo, que inclui e amplia o 'conhece-te a ti mesmo' (do Oráculo de Delfos, adotado por Sócrates) para um 'aprendamos a 
nos conhecer para pensarmos juntos', generalizando o 'penso, logo existo' (de Descartes) para um 'existimos eminentemente como comunidade' (que, por sua vez, reflete a visão de Kant), sugerindo, para Lévy (2000), a hipótese da emergência de um novo espaço antropológico ${ }^{1}$.

Nesse modelo, Lévy (2000, p.22) assinala que ao longo do tempo histórico as sociedades humanas desenvolveram espaços antropológicos a partir da possibilidade do primeiro grande espaço (a Terra) aberto à nossa espécie: "só os seres humanos vivem sobre a Terra; os animais habitam em nichos ecológicos". Os modos de conhecimento específicos desse primeiro espaço são os mitos e os ritos: a identidade "se inscreve ao mesmo tempo no vínculo com o cosmo e na relação de filiação ou de aliança com outros homens" (LÉVY, 2000, p.23). O segundo espaço, o Território, teria emergido com o neolítico e suas inovações sócio-culturais: a agricultura, a cidade, o estado e a escrita. Neste espaço os modos de conhecimento dominantes já se baseiam na escrita: “começa a história e o desenvolvimento dos saberes de tipo sistemático, teórico ou hermenêutico" e surgem as instituições orientadas por lógicas de pertencimento ou de exclusão. O terceiro espaço, das Mercadorias, tem o fluxo como princípio organizador: fluxo de energias, de matérias-primas, mercadorias, capitais, mão-de-obra, informações. Este espaço não elimina os anteriores, contudo,

[...] supera-os em velocidade. É o novo motor da evolução. A riqueza não provém do domínio das fronteiras, mas do controle dos fluxos. Daí por diante reina a indústria, no sentido amplo de tratamento da matéria e da informação. A ciência experimental moderna é um modo de conhecimento típico do novo espaço [...] Desde o fim da Segunda Guerra Mundial ela passa a dar lugar a uma 'tecnociência', movida por uma dinâmica permanente da pesquisa e da inovação econômica. (LÉVY, 2000, p.24)

É nesse contexto que emerge, na sociedade contemporânea, o espaço caracterizado pela "inteligência e [...] saber coletivos, cujo advento definitivo não está em absoluto garantido por certas "leis da história"” (LÉVY, 2000, p.24) e que teria a vocação de comandar os demais espaços. Nesse espaço do saber, as tecnologias digitais de informação e comunicação nos permitem criar e percorrer mundos virtuais, colocando sobre novas bases os problemas do laço social e abrindo possibilidade não somente para pensarmos coletivamente a aventura humana, mas, principalmente, para influenciá-la "mediante invenção de formas de pensar e se relacionar que contribuam para fazer emergir inteligências coletivas na humanidade" (LÉVY, 2000, p.33). Na sociedade contemporânea, que conjuga o futuro no presente, isto se tornaria inadiável porque "o saber tornou-se a nova infra-estrutura" (LÉVY, 2000, p.19).

${ }^{1}$ Definido como "um sistema de proximidade (espaço) próprio do mundo humano (antropológico) e, portanto, dependente de técnicas, de significações e das emoções humanas" (LÉVY, 2000, p.23). 
Para Lévy (2000, p.18), a nova dimensão da comunicação humana no espaço do saber deveria nos permitir "compartilhar nossos conhecimentos e apontá-los uns para os outros, o que é a condição elementar da inteligência coletiva". O problema da inteligência coletiva, nesse contexto, seria inventar uma linguagem "para além da escrita", ou um processo de comunicação "para além da própria linguagem", de tal modo que o "tratamento da informação pudesse ser distribuído e coordenado por toda parte" (LÉVY, 2000, p. 18). Por sua vez, no espaço do saber seria necessário "engajar a singularidade, a própria identidade pessoal na vida profissional", numa dupla mobilização subjetiva, "bastante individual, de um lado, mas ética e cooperativa, de outro" (LÉVY, 2000, p. 23. Em itálico, no original). ${ }^{2}$ Nesse contexto, a inteligência coletiva representaria a possibilidade de uma sociedade humana mundialmente conectada em rede e fundada no "reconhecimento e enriquecimento mútuo das pessoas" (LÉVY, 2000, p.27). Contudo, o autor esclarece que

[...] a inteligência coletiva não é um conceito exclusivamente cognitivo. Inteligência deve ser compreendida aqui como na expressão 'trabalhar em comum acordo' [...] Trata-se de uma abordagem de caráter bem geral da vida em sociedade e de seu possível futuro. [...] Essa visão de futuro organiza-se em torno de dois eixos complementares: o da renovação do laço social por intermédio do conhecimento e o da inteligência coletiva propriamente dita. (LÉVY, 2000, p.26. Em itálico, no original)

Uma inteligência distribuída por toda parte: eis o axioma proposto por Lévy. Para ele, a inteligência coletiva tem início com a cultura e cresce com ela, pois pensamos "com idéias, línguas, tecnologias cognitivas recebidas de uma comunidade" que nos antecedeu (LÉVY, 2000, p.29). Em um coletivo inteligente, a comunidade assumiria como objetivo a "negociação permanente da ordem estabelecida, de sua linguagem, do papel de cada um, o discernimento e a definição de seus objetos, a reinterpretação de sua memória" (LÉVY, 2000, p.31). Desse modo, o projeto da inteligência coletiva coloca-se como um "processo de crescimento, de diferenciação e de retomada recíproca das singularidades", e nele uma engenharia do laço social torna-se extremamente relevante podendo ser vista como "a arte de suscitar coletivos inteligentes e valorizar ao máximo a diversidade das qualidades humanas" (LÉVY, 2000, p.32. Em itálico, no original). O núcleo da engenharia do laço social é a economia das qualidades humanas e sua ação implica uma ética da inteligência coletiva, encarnada num grupo da humanidade que Lévy chama de justos (LÉVY, 2000, p.33).

Para exemplificar essa ética e seus praticantes, Lévy (2000, p.35) usa uma história bíblica bem presente no imaginário ocidental, como segue:

\footnotetext{
${ }^{2}$ Nesse ponto, e a nosso ver, encontramos na utopia de Lévy (2000) indícios da filosofia de Pascal, conforme descrita por Goldmann (1979).
} 
[...] Gênesis, capítulos 18 e 19. Um grande clamor se ergue contra Sodoma e Gomorra devido a seus pecados. Tendo Deus resolvido destruir essas cidades, nas quais se cometiam muitas injustiças, decide falar primeiro a Abraão. [...] o patriarca enceta com o Eterno uma extraordinária sessão de negociação: "Talvez haja cinqüenta justos na cidade! [...] Sucederia ao justo o mesmo que ao culpado?" [Na negociação,] Deus concede a Abraão a salvação da cidade, caso ali se encontrassem [...] dez justos apenas.

Ao cair da noite, dois anjos chegam às portas de Sodoma. Nada, em sua aparência, indica que sejam enviados de Deus. Para todos, são pessoas de passagem [...] Lot, que estava sentado à entrada da cidade, convida esses estrangeiros à sua casa [...] segundo as regras da hospitalidade. Eles ainda não haviam se deitado quando a população de Sodoma se reúne em torno da casa de Lot e pede para ver os estrangeiros, 'para deles abusar'. Lot se recusa a entregar seus hóspedes [...] A demonstração permitiu contar o número de justos em Sodoma: apenas um. [...]"

$\mathrm{Na}$ interpretação de Lévy (2000, p.36 a 39 passim. Em itálico, no original), o texto mostra

[...] a força de pessoas vivas e ativas, os 'justos', capazes de trabalhar para a existência do mundo humano.

Qual o crime de Sodoma? A recusa à hospitalidade. [...] Ora, a hospitalidade representa eminentemente o sustentáculo do laço social, concebido segundo a forma da reciprocidade: o hóspede é tanto aquele que recebe como o que é recebido. $\mathrm{E}$ cada um deles pode se tornar estrangeiro. [...] A hospitalidade consiste em atar o indivíduo a um coletivo. Contrapõe-se inteiramente ao ato de exclusão. O justo inclui, "insere", reconstitui o tecido social. Em uma sociedade de justos, e segundo a forma de reciprocidade, cada um trabalha para incluir os outros. [No mundo contemporâneo] onde tudo se move, onde todos são levados a mudar, a hospitalidade, moral dos nômades e migrantes, torna-se moral por excelência.

Por que é preciso ao menos dez justos para que a cidade seja poupada? [...] Porque é preciso uma força coletiva para manter um coletivo. [...] Dez é o início do anonimato. São necessários pelo menos dez, pois os justos devem ter passado pela prova da sociedade dos justos. [...] Os justos só são eficazes, só conseguem manter a existência de uma comunidade constituindo uma inteligência coletiva.

Abraão é o justo por excelência.[(...] Ao negociar com Deus [...] ele valoriza e desdobra ao máximo o potencial do bem; chama atenção para a bondade dos outros. [E] inventa a engenharia do laço social.

Assim, a negociação de Abraão com Deus representaria a primeira tecnologia de otimização dos efeitos das menores qualidades positivas presentes em um coletivo humano: seja em nível das empresas, das administrações, ou ainda das regiões ou nações, na sociedade em rede as necessidades econômicas deverão se associar à exigência ética, pois "na economia do futuro, o capital será o homem total" (LÉVY, 2000, p.42).

Essa visão humanista do futuro nos leva de volta à História da utopia planetária de Mattelart (2002, p.230), que reconhece Paul Otlet e Henri La Fontaine como "visionários da universalidade do conhecimento humano". Mattelart (2002, p.47-48) os considera como fundadores de uma "nova ciência da organização sistemática da documentação", iniciativa 
que, a seu ver, "é produto de um espírito visionário", característica que Figueiredo (1996) já havia ressaltado, em texto sobre Otlet e o Centenário da Federação Internacional de Informação e Documentação. Matterlart (2002, p.232) assinala que o texto de Otlet e La Fontaine sobre o 'conhecimento universal' é ao mesmo tempo um programa de ação e uma síntese do espírito das realidades do 'internacionalismo', um termo que nesta perspectiva não seria mais exclusivo do socialismo. Na sua História, o autor descreve o campo privilegiado de ação de Otlet e La Fontaine como ‘documentação', e esclarece que

[...] apesar de não ter cunhado o termo, eles fazem dele a base de uma nova ciência, tendo criado, em 1895, o Instituto Internacional de Bibliografia, com o objetivo de estudar 'as questões concernantes ao Livro e à organização sistemática da Documentação em bases internacionais e universais'. (MATTELART, 2002, p.233),

Esse Instituto promoveu, em 1910, o primeiro congresso mundial das associações internacionais, onde se decidiu o lançamento da revista La Vie internacionale, que seria portavoz de uma recém criada União das Associações Internacionais, à qual aderiram de imediato 32 organizações. A perspectiva social da União era indicada no programa: "Contribuir para desenvolver as relações além das fronteiras, para crescer a solidariedade humana e para assegurar a paz entre as nações" (MATTELART, 2002, p.233 e 234); sua "expressão lírica" foi transcrita como: "Fazer do mundo uma só cidade e de todos os povos uma só família". A proposta de Otlet e La Fontaine tinha como objetivo não somente a universalização do conhecimento, mas, especialmente, que todos tivessem acesso à informação, a qual representaria a possibilidade de realização do conhecimento no indivíduo, no seu grupo e na sociedade. Nesse sentido, é possível entender como visionária "a idéia de bibliografia como registro, memória do conhecimento científico, desvinculada dos organismos, como arquivos e bibliotecas, e de acervos" (PINHEIRO, 1997, p.28), assim como identificar nas atividades do Instituto a origem da Ciência da Informação no contexto da emergência do espaço do saber.

E aqui, relacionamos a utopia planetária de Otlet e La Fontaine ao conceito de inteligência coletiva de Lévy e ambos ao contexto da Internet $^{3}$, a qual engendra um mundo virtual que propicia possibilidades reais para criação de novas formas de universalização do conhecimento humano. Nesse sentido, temendo que o ciberespaço seja reservado à elite, Lévy (2000, p.65) destaca a necessidade e urgência de democratizar o acesso às tecnologias digitais de informação e comunicação, de modo a oferecer "a uma coletividade o meio de proferir um discurso plural, sem passar por representantes”. Suas previsões são de que

\footnotetext{
${ }^{3}$ Ver FREIRE, 2005.
}

InCID: R. Ci. Inf. e Doc., Ribeirão Preto, v. 1, n. 2, p. 122-132, jul./dez. 2010. 
[...] a capacidade mínima para navegar no ciberespaço se adquirirá provavelmente em tempo muito menor que o necessário para aprender a ler e, como a alfabetização, será associada a muitos outros benefícios sociais, econômicos e culturais além do acesso à cidadania. [...] A democracia em tempo real visa a constituição do 'nós' mais rico. ${ }^{4}$ (LÉVY, 2000, p.63 e 67)

Como acredita que as redes de comunicação e as memórias digitais serão, em breve, suporte para a maioria das representações e mensagens em circulação no planeta, Lévy (2000) defende a hipótese de que é possível, e até desejável, produzir dispositivos que encarnem ou materializem efetivamente a inteligência coletiva:

[...] temos em mente vastas redes digitais, memórias, informáticas, interfaces multimodais interativas, rápidas e nômades das quais os indivíduos poderão se apropriar facilmente. Imaginamos, sobretudo, uma relação com o saber diferente da que hoje prevalece, a instauração de um espaço de comunicação não-midiático, uma profunda renovação das relações humanas [...] uma reinvenção da democracia. (LÉVY, 2000, p.94).

Desse modo, Lévy (2000, p.208 e 147) termina por afirmar sua inteligência coletiva como "uma utopia do instável e do múltiplo", que responderia "a uma ética do melhor, mais que a uma moral do Bem", definindo os coletivos intelectuais como "meios humanos que encorajam as subjetividades a se singularizar continuamente". Para ele, "o projeto da inteligência coletiva não adia a [possibilidade da] felicidade para mais tarde [dando] seqüência à proposta de emancipação da filosofia das Luzes" (LÉVY, 2000, p.209). É esse quadro referencial que nos permite situar a inteligência coletiva de Lévy (2000) no âmbito das utopias planetárias $^{5}$ e, como corolário, indício de uma consciência possível para uma ética na sociedade em rede. Na Figura 1, a seguir, desenhamos a rede do texto, tendo como atrator conceitual (cf. WERSIG, 1993) o construto inteligência coletiva:

\footnotetext{
${ }^{4}$ A propósito do sujeito coletivo ('Nós'), observem o que diz Goldmann (1979, p.18-19): “[...] Quase nenhuma ação humana tem por sujeito um indivíduo isolado. O sujeito da ação é um grupo, um 'Nós', mesmo se a estrutura atual da sociedade, pelo fenômeno da reificação, tende a encobrir esse 'Nós' e a transformá-lo numa soma de várias individualidades distintas e fechadas umas às outras. Há entre os homens uma outra relação possível além da relação de sujeito a objeto ou da de Eu e Tu: é uma relação de comunidade que chamaremos o 'Nós', expressão de uma ação comum sobre um objeto físico ou social" (Em itálico, no original).

${ }^{5}$ No texto, Lévy (2000, p.208) esclarece que "Perguntar se o projeto da inteligência coletiva é 'utópico' ou 'realista' não faz [...] muito sentido: ele está lançado e ainda não sabemos, em meio à mobilidade geral, que limites deslocará e até que ponto". Contudo, e a nosso ver, quando diz que "Com o projeto da inteligência coletiva, damos seqüência à proposta de emancipação da filosofia das Luzes”, Lévy (2000, p.210) está revelando os indícios utopistas de sua proposta de uma "inteligência coletiva" como projeto para a sociedade
}

InCID: R. Ci. Inf. e Doc., Ribeirão Preto, v. 1, n. 2, p. 122-132, jul./dez. 2010. 


\section{Campo científico da informação:}

Construtos teóricos e metodológicos

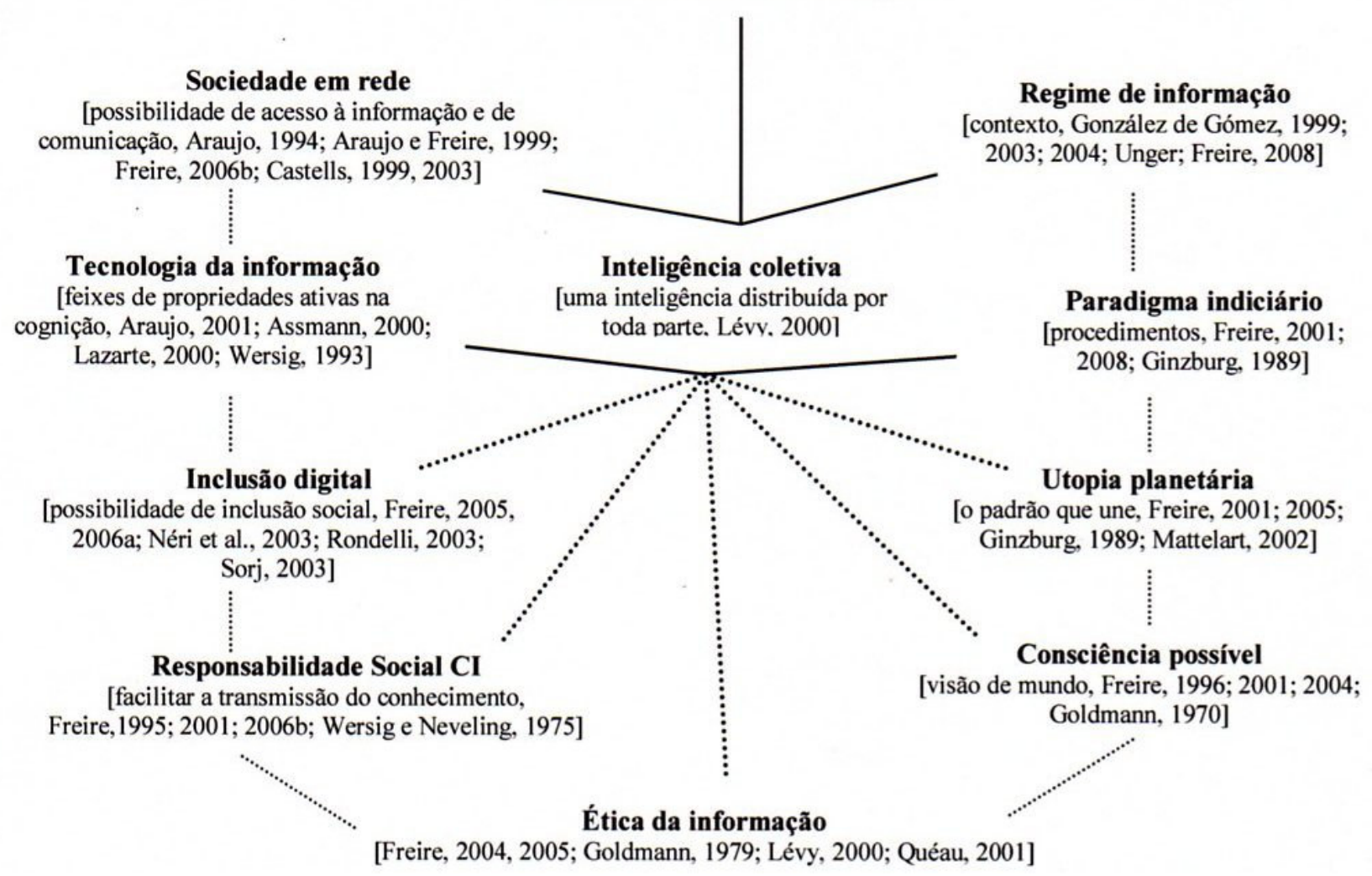

FIGURA 1 - Rede conceitual do texto.

Legenda: Linha contínua $=$ a urdidura da rede; Linha pontilhada $=$ os fios da trama Fonte: FREIRE, 2010. Adaptado de WERSIG, 1993; FREIRE, 2001.

\section{Considerações Finais}

Nesse cenário de transformações reais, cresce a responsabilidade social dos profissionais da informação, tanto como produtores de conhecimento no campo científico quanto como facilitadores na comunicação da informação para usuários que dela necessitem, na sociedade, independentemente dos espaços sociais onde vivem e dos papéis que desempenham no sistema produtivo. Crescem, também, as possibilidades de serem criados instrumentos para efetiva comunicação da informação e do conhecimento, de modo a apoiar atividades que fazem parte do próprio núcleo de transformação da sociedade: "Pois embora a informação sempre tenha sido uma poderosa força de transformação, o capital, a tecnologia, a multiplicação dos meios de comunicação de massa e sua influência na socialização dos indivíduos deram uma nova dimensão a esse potencial” (ARAUJO, 2001, p.15).

Pois atualmente estamos presenciando a 'nova relevância de um fenômeno antigo', a 
informação, cuja área de ação e atuação, ao longo do século XX, cresceu de tal modo a identificar-se com a sociedade contemporânea, qualificada como 'sociedade da informação'. Neste contexto, acrescentamos a contribuição de Quéau (2001, p.480) ao quadro das utopias planetárias, quando coloca que "o mundo precisa de uma visão, de um projeto que possa levar em conta [todos os indivíduos], especialmente os mais pobres e mais deserdados". Como Lévy (2000), ele elege o estrangeiro o símbolo da diferença por ser a imagem do 'outro', lembrando que existem muitos 'outros': “o desempregado, o pobre ou o iletrado. [Estes,] quase por natureza, são excluídos da sociedade da informação” (QUÉAU, 1998, p.270).

Enfim, encerrando essas breves reflexões, podemos considerar que no caso de uma ética para a sociedade da informação não há um manual de procedimentos a ser consultado, nem tampouco um mapa do caminho a seguir. O que, de certo modo, representa uma oportunidade histórica para a discussão, pelos profissionais da informação, sobre formas de atuação como inteligência coletiva, no sentido de pensar e desenvolver modos e meios para inclusão digital de populações social e economicamente carentes, pari passu com ações pela cidadania e inclusão social.

Transportar, nas asas da informação ${ }^{6}$, o conhecimento para todos aqueles que dele necessitem: esta seria, a nosso ver, a parte que nos cabe na tarefa coletiva de construir uma sociedade em rede democrática e justa.

Porém, este é um trabalho que as utopias planetárias podem até inspirar, e um sujeito coletivo como a Ciência da Informação pode até tomar como mote. Mas que caberá aos sujeitos individuais realizarem no anonimato existencial de cada vida, desde que vivida para apostar na unidade do gênero humano e numa filosofia de mútua reciprocidade e solidariedade. Para não esquecer que o ‘outro' sou eu, na dupla hélice do DNA.

\footnotetext{
${ }^{6}$ Uma metáfora que criamos para o conceito de informação como "representação do conhecimento" (Farradane, 1980) e usamos para ilustrar a proposta de Wersig e Neveling (1975) sobre a responsabilidade social da Ciência da Informação.
}

InCID: R. Ci. Inf. e Doc., Ribeirão Preto, v. 1, n. 2, p. 122-132, jul./dez. 2010. 


\section{Referências}

ARAUJO, V. M. R. H. de. Miséria informacional: o paradoxo da subinformação e superinformação. Revista Inteligência Empresarial, Rio de Janeiro, n. 7, abr. 2001.

Sistemas de recuperação da informação: nova abordagem teórico-conceitual. 1994. Tese (Doutorado em Comunicação e Cultura)-Escola de Comunicação, Universidade Federal do Rio de Janeiro, Rio de Janeiro, 1994.

ARAUJO, V.M.R.H. de; FREIRE, I.M. Conhecimento para o desenvolvimento: reflexões para o profissional da informação. Informação \& Sociedade: Estudos, João Pessoa, v. 9, n. $1,1999$.

ASSMANN, H. A metamorfose do aprender na sociedade da informação. Ciência da Informação, Brasília, v. 29, n. 2, 2000

CASTELLS, M. A galáxia da Internet: reflexões sobre a Internet, os negócios e a sociedade. Rio de Janeiro: Jorge Zahar, 2003.

A sociedade em rede. São Paulo: Paz e Terra, 1999.

FARRADANE, J. Knowledge, information and information science. Journal of Information Science, Cambridge, v. 2, 1980.

FIGUEIREDO, N. Paul Otlet e o centenário da FID. In: ORGANIZAÇÃO DO CONHECIMENTO E SISTEMAS DE CLASSIFICAÇÃO. Brasília: IBICT, 1996.

FREIRE, I. M. Um olhar sobre a produção científica brasileira na temática epistemologia da ciência da informação. Tendências da Pesquisa Brasileira em Ciência da Informação, João Pessoa, v. 1, n. 1, 2008.

Janelas da cultura local: abrindo oportunidades para inclusão digital de comunidades. Ciência da Informação, Brasília, v.35, n.3, 2006a.

Acesso à informação e identidade cultural: entre o global e o local. Ciência da Informação, Brasília, v. 35, n. 2, 2006 b.

A utopia planetária de Pierre Lévy: uma leitura hipertextual d'a inteligência coletiva.

Perspectivas em Ciência da Informação, Belo Horizonte, v. 10, n. 2, 2005.

O desafio da inclusão digital. Transinformação, Campinas, v. 16, n. 2, 2004.

O futuro é agora. Revista Você S/A, agosto de 2003.

A responsabilidade social da ciência da informação e/ou $O$ olhar da consciência possível sobre o campo científico. 2001. Tese (Doutorado em Ciência da Informação)IBICT,Universidade Federal do Rio de Janeiro, Rio de Janeiro, 2001.

25, n. 3, 1996.

O desviante secreto: um exercício conceitual. Ciência da Informação, Brasília, v. 
Informação; consciência possível; campo. Um exercício com construtos teóricos.

Ciência da Informação, Brasília, v. 24, n. 1, 1995.

GINZBURG, C. Mitos, emblemas, sinais: morfologia e história. São Paulo: Cia. das Letras, 1989.

GOLDMANN, L. Dialética e cultura. Rio de Janeiro: Paz e Terra, 1979.

Importância do conceito de consciência possível para a informação. In:

COLÓQUIOS FILOSÓFICOS DE ROYAUMONT. O conceito de informação na ciência contemporânea. Rio de Janeiro: Paz e Terra, 1970.

GONZÁLEZ DE GÓMEZ, M. N. Novas fronteiras tecnológicas das ações de informação: questões e abordagens. Ciência da Informação, Brasília, v. 33, n. 1, 2004.

Escopo e abrangência da Ciência da Informação e a Pós-Graduação na área: anotações para uma reflexão. Transinformação, Campinas, v. 15, n. 1, 2003.

Da política de informação ao papel da informação na política contemporânea.

Revista Internacional de Estudos Políticos, Rio de Janeiro, v. 1, n. 1, p. 57-93, 1999.

LÉVY, P. A inteligência coletiva: por uma antropologia do ciberespaço. São Paulo: Loyola, 2000 .

LAZARTE, L. Ecologia cognitiva na sociedade da informação. Ciência da Informação, Brasília, v. 29, n. 2, 2000.

MATTELART, A. História da utopia planetária: da cidade profética à sociedade global. Porto Alegre: Sulina, 2002.

NERI, M.et al. Lei de Moore e políticas de inclusão digital. Revista Inteligência Empresarial, Rio de Janeiro, n. 14, jan. 2003.

PINHEIRO, L. V. R. A ciência da informação entre sombra e luz: domínio epistemológico e campo interdisciplinar. 1997. Tese (Doutorado em Comunicação e Cultura)-Escola de Comunicação, Universidade Federal do Rio de Janeiro, Rio de Janeiro, 1997.

QUÉAU, P. Cibercutlura e info-ética. In: MORIN, E. (Org.). A religação dos saberes: o desafio do século XXI. Rio de Janeiro: Bertrand Brasil, 2001.

A revolução da informação: em busca do bem comum. Ciência da Informação, Brasília, v. 27, n. 2, 1998.

RONDELLI, E. Quatro passos para a inclusão digital. 2003. Disponível em:

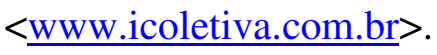

SORJ, B. brasil@ povo.com: a luta contra a desigualdade na sociedade da informação. Rio de Janeiro: Jorge Zahar; Brasília: Unesco, 2003.

UNGER, R. J. G.; FREIRE, I. M. Regimes de informação na sociedade da informação: uma contribuição para a gestão da informação. Revista Digital de Biblioteconomia e Ciência da Informação, Campinas, n. 2, 2008. 
WERSIG, G. Information science: the study of postmodern knowledge usage. Information Processing \& Management, Elmsford, v. 29, n. 2, 1993.

WERSIG, G.; NEVELING, U. The phenomena of interest to information science. The Information Scientist, London, v. 9, n. 4, 1975.

Artigo submetido em 29 out. 2010

Artigo aceito em 29 nov. 2010 